\title{
Spatial variability of wave energy resources around the Canary Islands
}

\author{
H. Chiri, M. Pacheco \& G. Rodríguez \\ Departamento de Física, Universidad de Las Palmas \\ de Gran Canaria, Spain
}

\begin{abstract}
Spatial variability of wave energy resource around the coastal waters of the Canary Archipelago is assessed by using a long-term data set derived by means of hindcasting techniques. Results reveal the existence of large differences in the energetic content available in different zones of the archipelago, mainly during spring and autumn. Areas with a higher wave power level are the north edge of Lanzarote, western side of Lanzarote and Fuerteventura, north and northwest in La Palma and El Hierro, as well as the north coast of Tenerife. The available energy potential slightly decreases in the north side of Gran Canaria and La Gomera. In general, only north and west edges of the archipelago during winter and autumn show practical interest for the use of existing wave energy conversion devices.
\end{abstract}

Keywords: wave energy, spatial variability, wave hindcasting, Canary Islands.

\section{Introduction}

The search for renewable energy sources offering clean alternatives to scanty, expensive, and environmentally problematic fossil fuels represents a vital challenge for humankind. The research in this field has been during a long time almost exclusively focused on the development of solar and wind sources. However, solar energy is stored in the sea as waves, currents, and heat. That is, energy in the ocean is much more concentrated than in the direct solar radiation and in the wind.

Small islands and archipelagos in the world are almost totally dependent on fossil fuels to meet their energetic needs. Nevertheless, in general, islands have a unique potential for renewable energy (i.e., Jensen [1]). That is, a competitive 
economic situation for renewable energy technologies, good renewable energy resources, positive attitude towards renewable energy. Furthermore, there is a need to demonstrate feasibility of renewable energy in a large-scale, integrated and organised form. Therefore islands are very important and interesting for the promotion of renewable energy world-wide and almost all of the mature renewable energy technologies, mainly solar and wind, have been utilised for electricity production in these areas.

Wind-generated gravity waves in the sea surface constitute the highest energy density of all renewable energy resources (i.e., Clement et al. [2]). This fact has led scientists and engineers to develop a wide variety of devices to harness this resource by means of its conversion into electrical energy. An up-to-date review of the state-of-the-art in this challenging area is provided by Cruz [3]. Nowadays, this technology is not still at an advanced stage of development. However, it has attracted increasing interest of researchers during the past few decades as a potential energy resource to small islands. In particular, since the pioneering work of Mollison [4], Canary archipelago, as well as Azores and Madeira, have been considered as an interesting zone to exploit wave energy as a feasible alternative to conventional energy resources. Thus, several authors have conducted studies to assess the potential wave energy available for some specific islands (i.e., Rodríguez et al. [5], Iglesias and Carballo [6, 7], Sierra [8]).

The main goal of the present study is to extend the assessment of the potential availability of wave energy to all the islands of the Canary archipelago, with special emphasis on the spatial variability of this resource.

The paper is structured as follows. The study area and the data base used in the study are presented in section 2. General notions on the methodology to estimate the wave energy flux are briefly outlined in section 3 . Next, in section 4, the discussion of results derived from the analysis of the data set is presented. Conclusions drawn from results are summarised in section 5 .

\section{Study area and data set}

The Canary Islands are an archipelago of seven major volcanic islands in the Atlantic Ocean, located about $100 \mathrm{Km}$ off the African coast $\left(27.5^{\circ} \mathrm{N}-29.5^{\circ} \mathrm{N}\right.$, $13^{\circ} \mathrm{W}-18.5^{\circ} \mathrm{W}$ ) (Fig. 1). Gran Canaria and Tenerife represent the two most populated islands, adding together more than $80 \%$ of total inhabitants. The rest of the residents are mainly concentrated in Fuerteventura, Lanzarote and La Palma, while the minor islands of El Hierro and La Gomera are barely populated. A quick look at Figure 1 reveals the complex geometry of the islands coast, the proximity between them, and to the African continent. Another important factor to consider is the altitude of the islands. The altitude in five of the seven islands is over $1500 \mathrm{~m}$, with $3700 \mathrm{~m}$ in Tenerife, while Lanzarote and Fuerteventura are considerably flat.

The estimation of the wave energy potential around Canary Islands has been carried out by using time series of characteristic wave parameters obtained by means of a hindcasting approach. The WAM numerical model provides the 


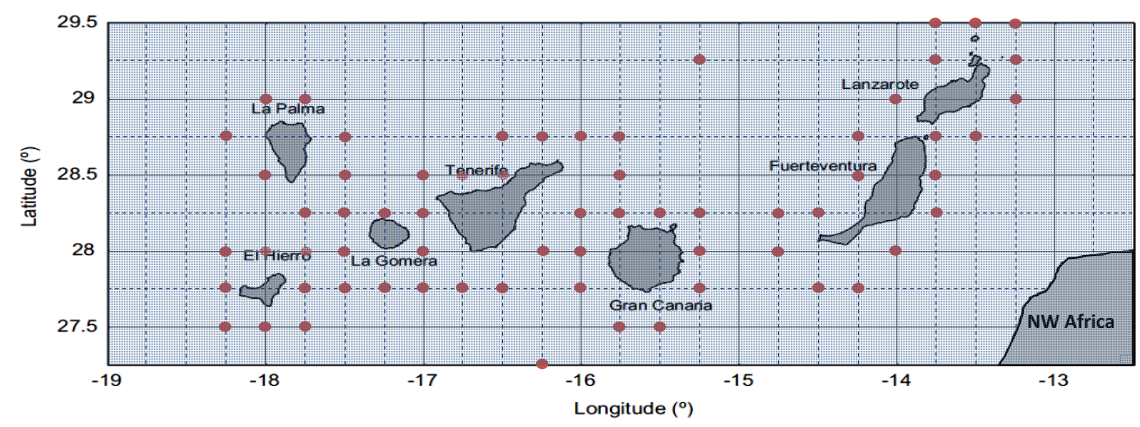

Figure 1: $\quad$ Map of the Canary Islands and location of the hindcast points.

directional spectrum at each one of the points marked in Fig. 1. From these, characteristic parameters to evaluate wave power resource can be derived.

The WAM model is a $3^{\text {rd }}$ generation spectral wave model which solves the spectral wave action balance equation without any a priori assumption on the wave spectrum shape by using a finite-difference scheme. The wave field is described by the two-dimensional wave action density spectrum, $N(\omega, \theta)$, where $\omega$ is the angular wave frequency and $\theta$ is the wave direction. The model uses wave action density spectrum because action density is conserved in the presence of currents. The spectral action balance equation reads

$$
\frac{\partial N}{\partial t}+\frac{\partial\left(C_{g x} N\right)}{\partial x}+\frac{\partial\left(C_{g y} N\right)}{\partial y}+\frac{\partial\left(C_{\omega} N\right)}{\partial \omega}+\frac{\partial\left(C_{\theta} N\right)}{\partial \theta}=\frac{s}{\omega}
$$

The first term on the left-hand side represents the local rate of change of wave action density in time; the second and third terms stand for the propagation of wave action over geographical space, with propagation velocities $C_{g x}, C_{g y}, C_{\omega}, C_{\theta}$ in the geographical and spectral space, respectively. The term at the right hand side is the source function, including the effects of generation, dissipation, nonlinear interactions, and bottom friction dissipation. Details about WAM can be found in Komen et al. [9].

The WAM model was used to provide the 44-year hindcast wave climate database (1958-2001) from the European HIPOCAS project (see Guedes Soares [10]). The model was forced by the output of a high-resolution atmospheric model (REMO regional atmospheric model). The HIPOCAS database was generated by running the models on a grid covering the North Atlantic with a resolution of $0.5^{\circ} \times 0.5^{\circ}$ far from the coast and $0.25^{\circ} \times 0.25^{\circ}$ close to this. Temporal resolution is 3 hours. Details on the methodology used to obtain wave conditions at any grid dot are given in Pilar et al. [11]. Figure 1 indicates the position of the 65 points considered in the study, indicated as red dots.

\section{Wave energy flux estimation}

The wave energy flux, power density, per meter of wave crest is given by

$$
P=\rho g \int_{0}^{2 \pi} \int_{2 \pi}^{\infty} C_{g}(f, h) S(f, \theta) d f d \theta
$$


where $\rho$ is the sea water density $(1025 \mathrm{Kg} / \mathrm{m} 3), g$ the acceleration due to gravity, $C_{g}(f, h)$ the group velocity for each frequency component, $\mathrm{h}$, the water depth, and $S(f, \theta)$ the directional wave spectrum, which is related to the omnidirectional wave spectrum, $S(f)$, by

$$
S(f)=\int_{0}^{2 \pi} S(f, \theta) d \theta
$$

The spectral moments of order $n$, denoted by $m_{n}$, are defined as

$$
m_{n}=\int_{0}^{2 \pi} \int_{0}^{\infty} f^{n} S(f, \theta) d f d \theta=\int_{0}^{\infty} f^{n} S(f) d f
$$

Various characteristic wave parameters can be defined in terms of the spectral moments. Thus, the significant wave height, $H_{S}$, is given by

$$
H_{s}=4\left(\int_{0}^{\infty} \int_{0}^{2 \pi} S(f, \theta) d \theta d f\right)^{1 / 2}=\left(\int_{0}^{\infty} S(f) d f\right)^{1 / 2}=4 \sqrt{m_{0}}
$$

The mean wave period, $T_{02}$, and the wave energy period, $T_{-1,0}=T e$, are defined by

$$
T_{0,2}=\left(\frac{m_{0}}{m_{2}}\right)^{1 / 2} \quad ; \quad T_{-1,0}=\left(\frac{m_{-1}}{m_{0}}\right)
$$

Then Eq. (1) can be rewritten as (Mollison [4])

$$
P=\frac{\rho g^{2}}{4 \pi} \int_{0}^{\infty} \frac{S(f)}{f} d f=\frac{\rho g^{2}}{4 \pi} m_{-1}=\frac{\rho g^{2}}{4 \pi} H_{S}^{2} T_{e}
$$

For $H_{S}$ in meters and $T_{e}$ in seconds, the energy flux per unit of wave crest is

$$
P=0.49 H_{S}^{2} T_{e} \quad\left(\frac{K w}{m}\right)
$$

\section{Results and discussion}

The mean annual wave power evaluated for each point is represented in Fig. 2, by means of circles of different size and colour. A large variability in the wave power availability along the coasts results evident. According to these results, it is possible to identify three different areas in terms of their average wave power. The first is that including the north and west coasts of Lanzarote and Fuerteventura, the north side of Gran Canaria and Tenerife, as well as the western side of the archipelago, including the north coast or La Palma. Wave power values in that areas range from 18 to $24 \mathrm{~kW} / \mathrm{m}$, with highest values observed in the northwest side of La Palma and El Hierro, as well as in the north coast of Lanzarote. The second area is characterized by mean wave power values lower than those of the first zone. Finally, south and east coasts of the islands 
constitute a third kind of area, with the lowest values of wave power, not exceeding $12 \mathrm{~kW} / \mathrm{m}$.

Values of average wave power for each climatic season are shown in Figs 3-6. During the spring (Fig. 3) the areas with higher energy power available are north and west strips of the archipelago, particularly the north edge of Lanzarote and La Palma islands. The general distribution follows the same pattern than that of the annual average values, with very low values of power in the south and southeast of the main part of the islands (3-9 kW/m), and intermediate values in the remaining areas.

Figure 4 illustrates the average wave power during summer. It reveals a significant reduction of the wave energy potential in the entire archipelago. Areas with larger energy availability remain the same, but now values are lower than $10 \mathrm{~kW} / \mathrm{m}$.

Energy levels corresponding to autumn are depicted in Fig. 5. During this season, energy levels are similar to those estimated for the annual period. However, power values in the areas with a higher exposure degree to wave fields approaching from the N-NW directional sector are comparatively higher. In the north and west of La Palma, as well as in the north of Lanzarote wave power level reaches values between 24 and $27 \mathrm{~kW} / \mathrm{m}$.

In contrast with the other periods of the year, during winter (Fig. 6) Canary Islands coasts receive a relatively height quantity of wave energy. In sheltered areas by shadowing effects, levels of energy follows been low, but in the other parts of the archipelago the available power experiences a considerable increase. This is maximum the northern and western edges of the archipelago, where wave power values increases between $75 \%$ and $80 \%$ with respect to the annual mean values. Zones with higher wave energy power are located norwest of La Palma, with a power level close to $40 \mathrm{~kW} / \mathrm{m}$, and to the north of Lanzarote, where wave energy power reaches values in the range $36-39 \mathrm{~kW} / \mathrm{m}$.

Results derived from the study reveals an appreciable spatial variability in the wave energy availability in the archipelago. The reasons for a so large variability are diverse. At one hand, waves can reach the coasts of the islands from any direction. Nevertheless, for a given direction of approach, waves only impact on that islands exposed to wave fields coming from that sector and, of that islands, only the coasts oriented in the direction of wave travel. That is, some islands can act as a, partial or total, barrier against some wave conditions for other islands. Furthermore, any island shelters their own coasts located at the opposite side of wave approaching. These effects of self-blockage and mutual-blockage depend to a large extent on the geometry and dimensions of each island. On the other hand, characteristics of wave fields traveling toward the islands depend substantially of the directional sector from which waves approach.

\section{Concluding remarks}

Analysis of wave energy potential around Canary Islands reveals that there are large differences in the energetic content available in different zones of the 


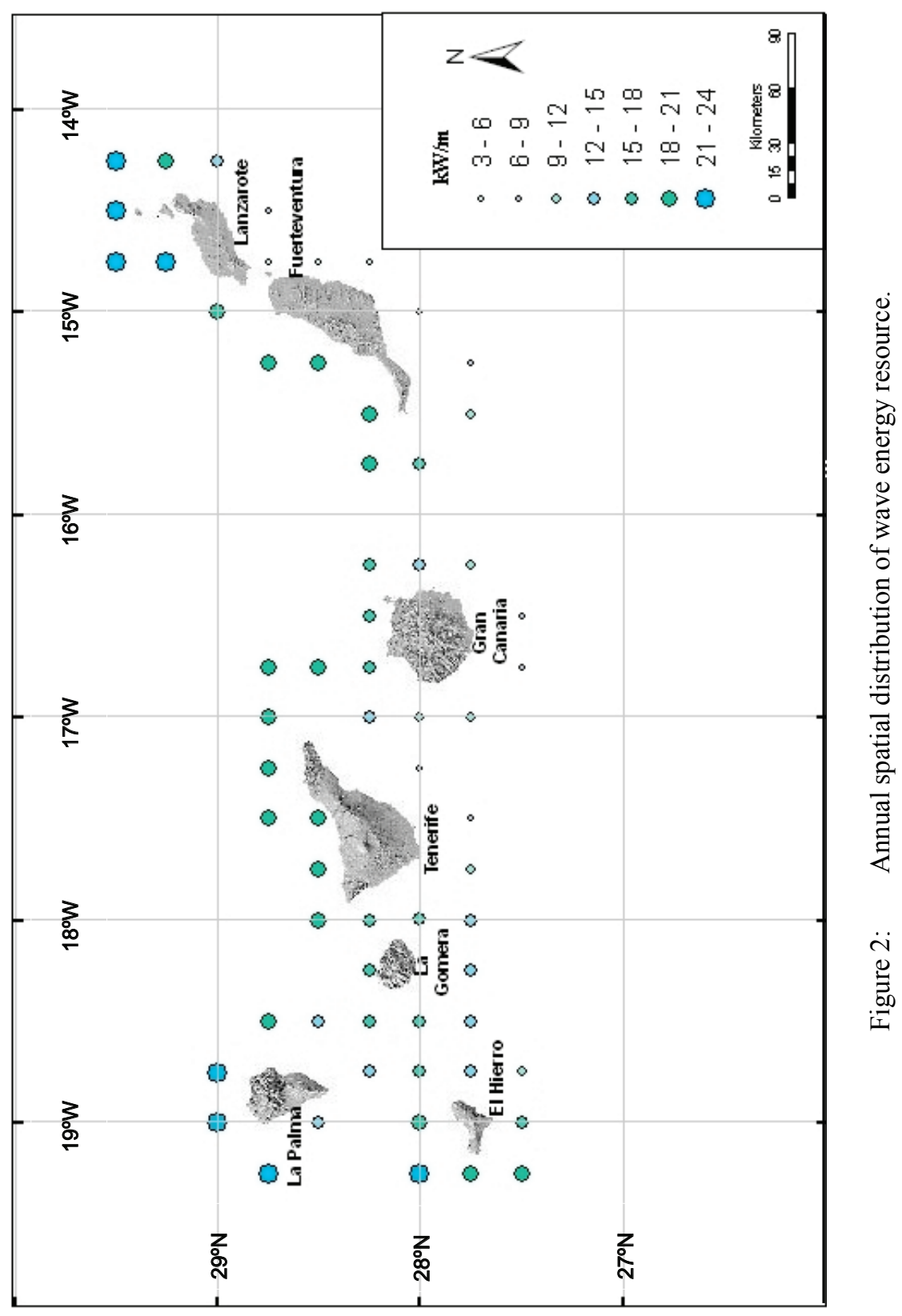




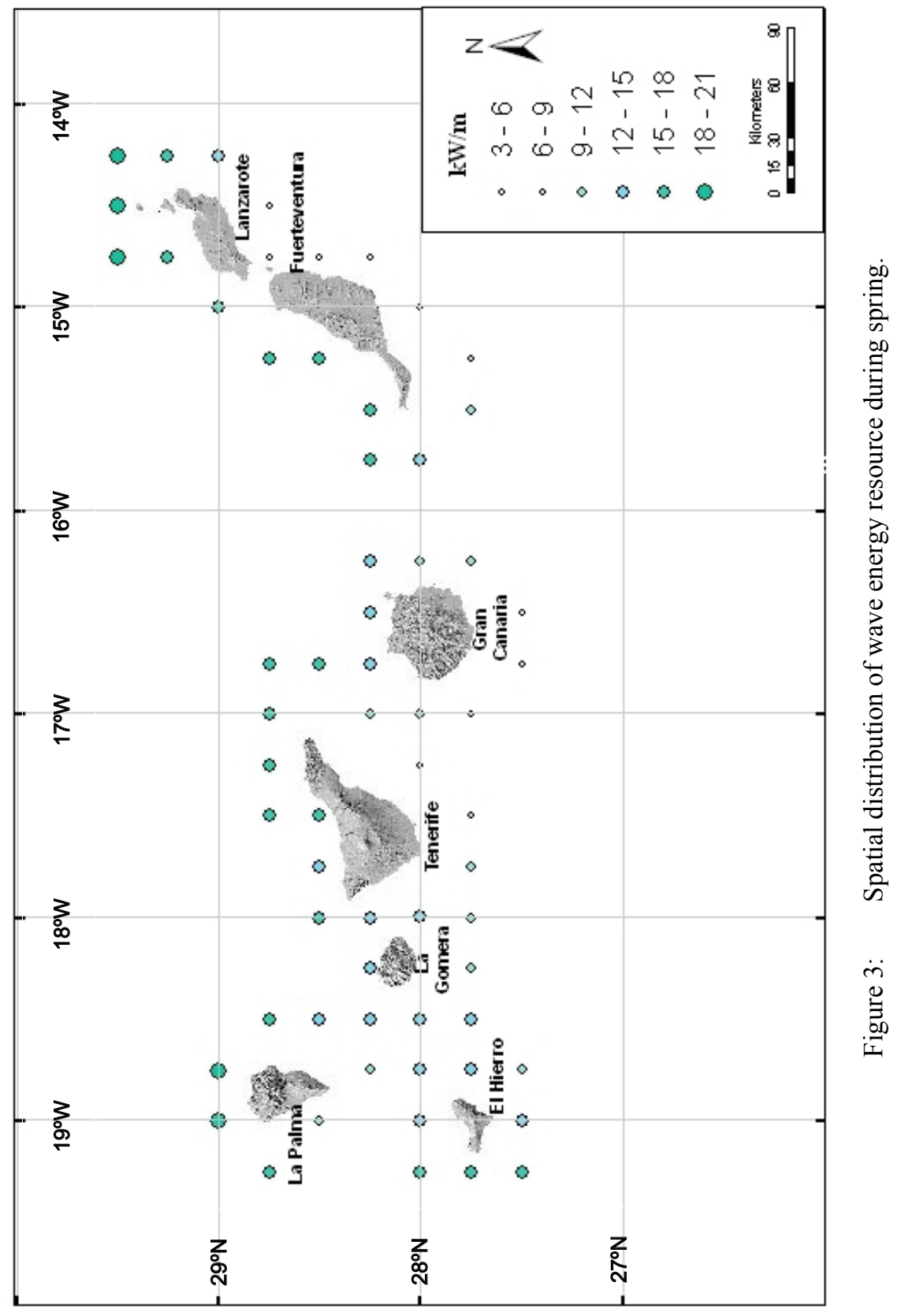




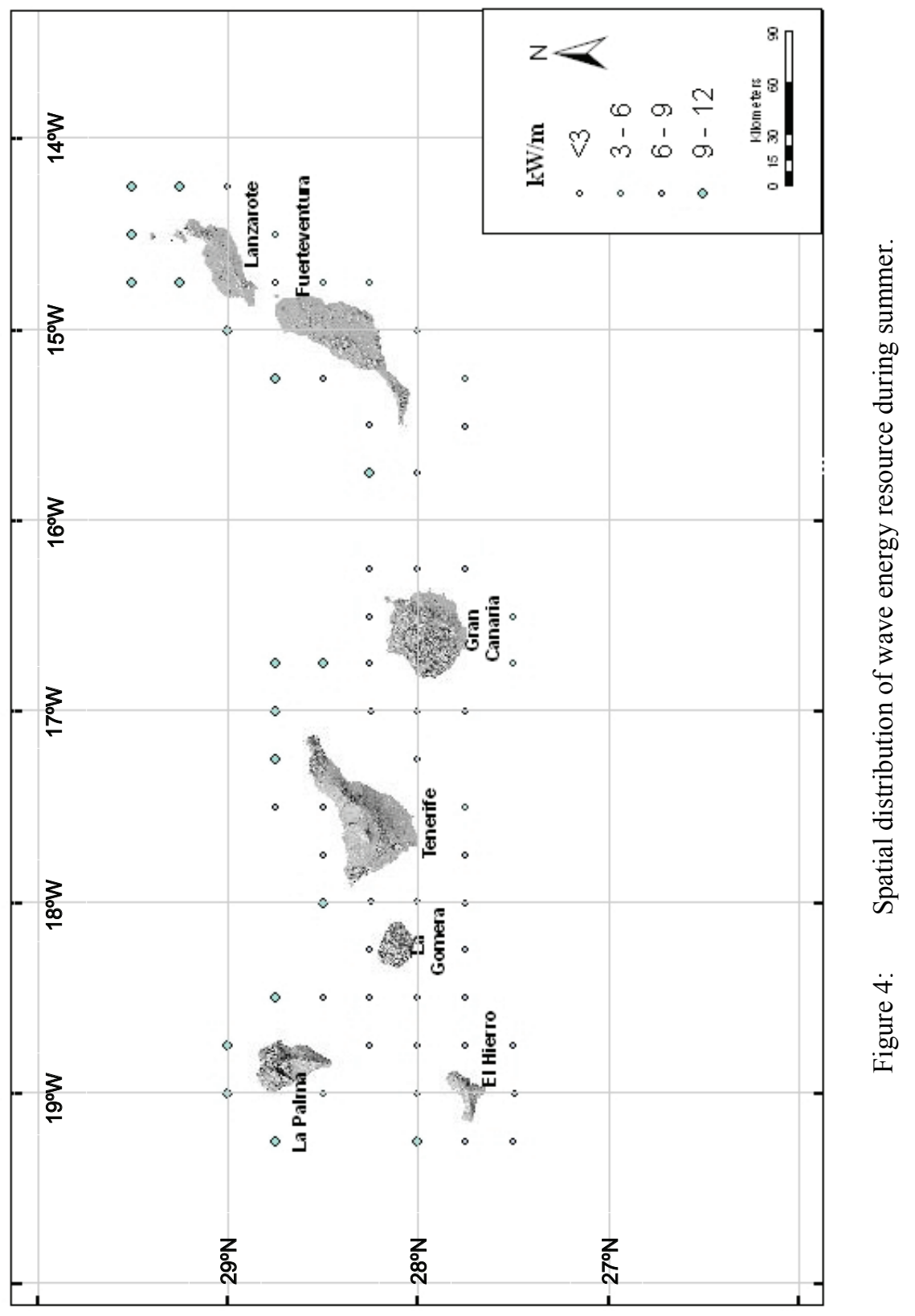




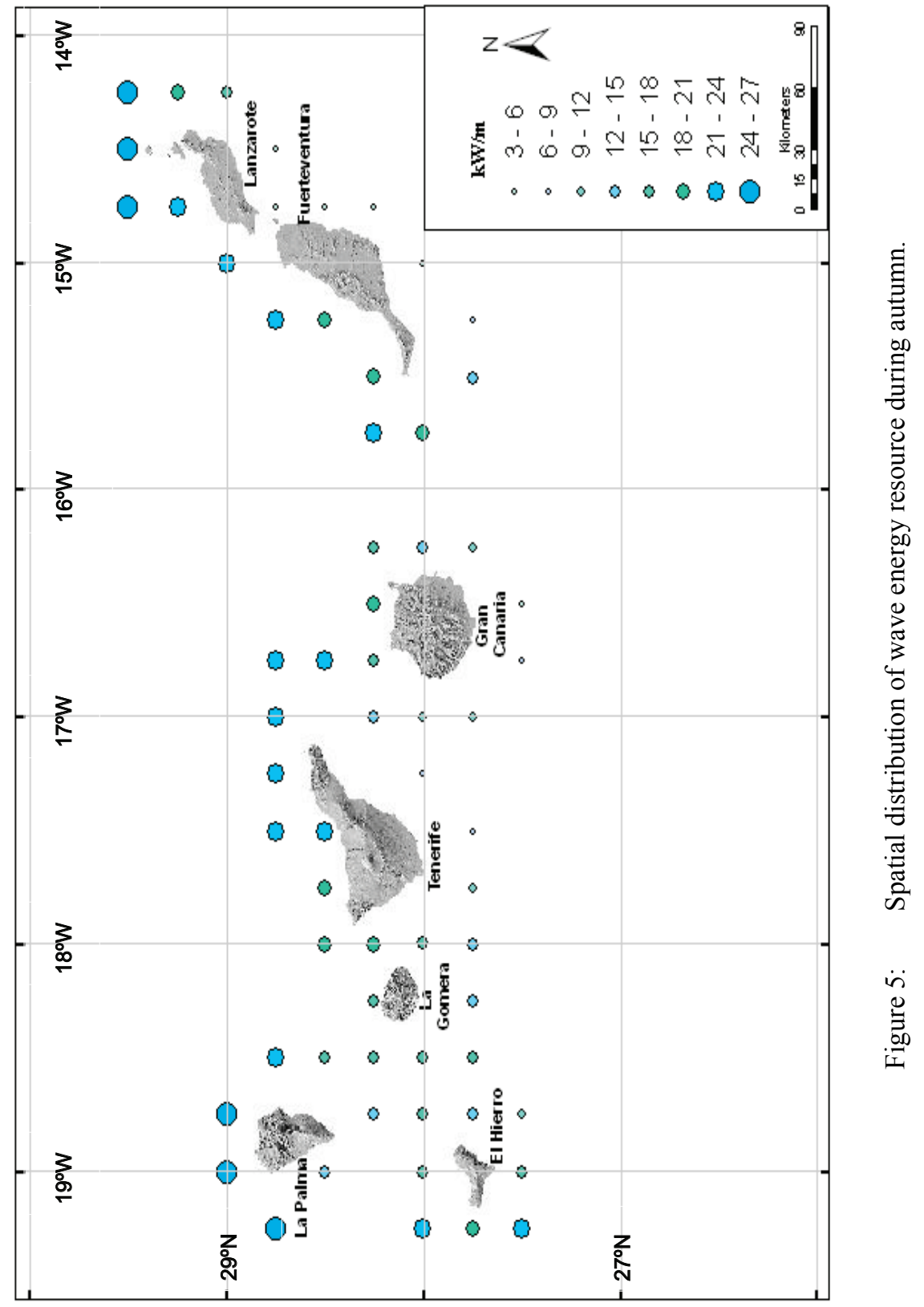




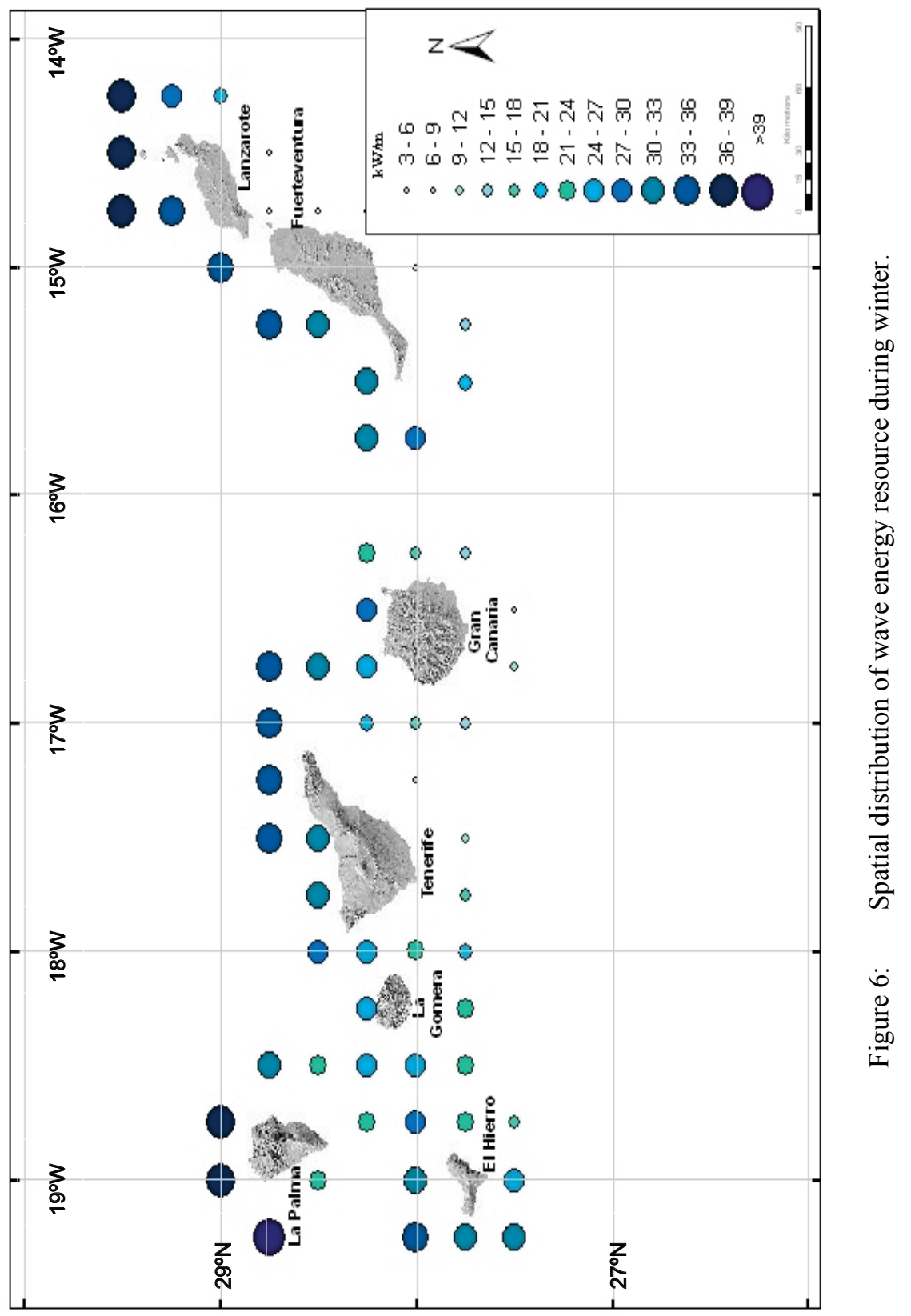


archipelago. Areas with a higher wave power level are the north edge of Lanzarote, western side of Lanzarote and Fuerteventura, north and northwest in La Palma and El Hierro, as well as the north coast of Tenerife. The available energy potential slightly decreases in the north side of Gran Canaria and La Gomera, in relation to the previous areas. These groups of sectors correspond to the coastal strips exposed to the wave storms and long travelled swell approaching to the islands from the N-NW directional sector. In particular, it is possible to highlight two areas with energy levels comparatively high: The north of Lanzarote Island and the north and west of La Palma. Mean power during the year in these areas ranges between 21 and $24 \mathrm{~kW} / \mathrm{m}$ (per unit of crest length) and the mean energy oscillates in the range $184-210 \mathrm{MWh} / \mathrm{m}$.

As a summary, the annual average values of wave energy content available in different coastal zones of the archipelago shows a large spatial variability. This variability is strengthened when considering the wave power average in different climatic seasons. Winter is the season of maximum wave energy availability. During autumn, the available energy level in these areas is still enough to implement existing wave energy conversion devices successfully. Values of available power can reduce up to $75 \%$ in summer. Spring, as summer, does not present interest in terms of the wave energy availability, with values always lower than the annual means.

\section{Acknowledgements}

The present research has been partially supported by Agencia Canaria de Investigación, Innovación y Sociedad de la Información (ACIISI), through research projects, SE10/17 (EXMAR) and ULPAPD-08/01-5 Recursos Ambientales en la Provincia de Las Palmas. The authors also would like to thank Puertos del Estado (Spanish Port Authority) for providing the data used in the study.

\section{References}

[1] Jensen, T.L., Forum for Energy and Development, Renewable Energy on Small Islands, Vesterkopi, 2000.

[2] Clement A., P. McCullen, A. Falcao, A. Fiorentino, F. Gardner, K. Hammarlund, G. Lemonis, T. Lewis, K. Nielsen, S. Petroncini, M.-Teresa Pontes, P. Schild, B-O. Sjostrom, H.C., Sørensen, T. Thorpe, Wave energy in Europe: current status and perspectives, Renewable and Sustainable Energy Reviews, 6, 405-431, 2002.

[3] Cruz J., Ocean wave energy: Current status and future perspectives, Springer, Bristol, 2008.

[4] Mollison D., Wave climate and the wave power resource, Hydrodynamics of Ocean Wave-Energy Utilization, Springer-Verlag, 133-156, 1985.

[5] Rodríguez G., Pacheco, M., González, J., Wind-wave energy assessment around Canary Islands, Proceedings of the MAREC-2002 International 
Conference on Marine Renewable Energy, Newcastle, U.K., 183-190, 2002.

[6] Iglesias G., Carballo R., Wave power for la Isla Bonita, Energy, 35: 5013$5021,2010^{\mathrm{a}}$.

[7] Iglesias G., Carballo R., Wave resource in El Hierro - an island towards energy self-sufficiency, Renewable Energy, 36: 689-698, 2010b

[8] Sierra, J.P., D. González-Marco, J. Sospedra, X. Gironella, C. Mösso, A. Sánchez-Arcilla, Wave energy resource assessment in Lanzarote (Spain). Renewable Energy 55, 480-489, 2013.

[9] Komen, G., L. Cavaliery, M. Donelan, K. Hasselmann, S. Hasselmann and P.A.E.M. Janssen, Dynamics and Modelling of Ocean waves, Cambridge Univ. Press, 1994.

[10] Guedes Soares C. Hindcast of dynamic processes of the ocean and coastal areas of Europe. Coastal Engineering, 55, 825-826, 2008.

[11] Pilar P, Guedes Soares C, Carretero JC. 44-year wave hindcast for the north east Atlantic European coast. Coastal Engineering, 55, 861-871, 2008. 